\title{
THE ACTIVATION ENERGIES OF TEMPERATE SNOW SAMPLES
}

\author{
By L. T. Traub and P. W. F. Gribbon \\ (School of Physical Sciences, University of St Andrews, St Andrews KYI6 9SS, Scotland)
}

Abstract. The temperature dependence of the high-frequency conductivity of snow was studied for eight samples in the range $-10^{\circ} \mathrm{C}$ to $-80^{\circ} \mathrm{C}$. The activation energies for granular snow varied from $0.60 \mathrm{eV}$ at temperatures down to $-25^{\circ} \mathrm{C}$ to $0.24 \mathrm{eV}$ at temperatures below $-25^{\circ} \mathrm{C}$, and for dry snow from $0.42 \mathrm{eV}$ to $0.18 \mathrm{eV}$ in the same temperature ranges. Dry snow samples had higher conductivities and lower activation energies than granular icy samples throughout the complete temperature range.

Volume and surface conduction processes were operative. At the higher temperatures above $-25^{\circ} \mathrm{C}$ volume conduction was attributed to Bjerrum defect migration, while at lower temperatures Bjerrum conduction was replaced by ionic-defect conduction. Granular samples which had experienced melting and refreezing on the surface of the crystals have a structural change which decreased the ionic-defect density at the surface and lowered the sample conductivity.

Above $-25^{\circ} \mathrm{C}$, the activation energies for granular icy snow were consistent with those for temperate glacier ice and for laboratory single and polycrystalline ice samples, but was not in agreement with those of either polar snow or ice. Below $-25^{\circ} \mathrm{C}$, the activation energies for granular snow were consistent with those for temperate glacier ice, containing impurities, and for polar snow and ice. Fresh dry temperate snow samples had lower activation energies than in situ polar snow.

RÉsumé. Energies d'activation des echantillons de neige tempérée. La dépendence avec la température de la conductivité haute fréquence de la neige a été étudiée avec huit échantillons dans le domaine de température compris entre - ro et $-80^{\circ} \mathrm{C}$. Les énergies d'activation pour la neige granulaire varient de $0,60 \mathrm{eV}$ pour des températures supérieures à $-25^{\circ} \mathrm{C}$ à $0,24 \mathrm{eV}$ pour des températures inférieures et, dans le cas de la neige sèche, de $0,42 \mathrm{eV}$ à $0,18 \mathrm{eV}$ dans les mêmes domaines de température. Les échantillons de neige sèche présentent une conductivité plus élevée et une énergie d'activation plus faible que les échantillons de neige granulaire à toutes températures.

Des processus de conduction en volume et en surface interviennent. Au-dessus de $-25^{\circ} \mathrm{C}$, la conduction en volume est attribuée à la migration des défauts de Bjerrum tandis qu'aux températures plus basses prédomine la conduction par défauts ioniques. Les échantillons granulaires qui ont subi une fusion et un regel en surface, présentent un changement structural correspondant à une décroissance de la densité de défauts ioniques à la surface et, ainsi, une diminution de la conductivité.

Au-dessus de $-25^{\circ} \mathrm{C}$, les énergies d'activation de la neige granulaire sont en accord avec celles observées dans le cas de la glace de glaciers tempérés ou dans le cas d'échantillons mono- ou polycristallins de glace de laboratoire; elles sont, par contre, différentes de celles obtenues avec la neige ou la glace polaire. Au-dessous de $-25^{\circ} \mathrm{C}$, les énergies d'activation pour la neige granulaire sont en accord avec celles de la glace des glaciers tempérés contenant des impuretés ainsi qu'avec celles de la neige et de la glace polaires. Les échantillons de neige fraiche, tempérée et sèche présentent des énergies d'activation plus faibles que celles obtenues in situ dans le cas de neige polaire.

Zusammenfassung. Die Aktivierungsenergien von temperierten Schneeproben. Die Temperaturabhängigkeit der Hochfrequenzleitfähigkeit von Schnee wurde an acht Proben im Bereich von $-10^{\circ} \mathrm{C}$ bis $-80^{\circ} \mathrm{C}$ untersucht. Die Aktivierungsenergien reichten für körnigen Schnee von o,6o eV (bei Temperaturen bis herab zu $-25^{\circ} \mathrm{C}$ ) bis zu $0,24 \mathrm{eV}$ (bei Temperaturen unterhalb $-25^{\circ} \mathrm{C}$ ) und für trockenen Schnee von 0,42 bis $0,18 \mathrm{eV}$ in denselben Temperaturbereichen. Trockene Schneeproben hatten im gesamten Temperaturbereich höhere Leitfähigkeiten und niedrigere Aktivierungsenergien als körnige, eisartige Proben.

Es waren Volumen- und Oberflächenleitfähigkeitsprozesse wirksam. Bei Temperaturen oberhalb $-25^{\circ} \mathrm{C}$ wurde die Volumenleitung der Wanderung von Bjerrumfehlern zugeschrieben, während bei niedrigeren Temperaturen die Bjerrumfehlerleitung durch Ionenfehlerleitung ersetzt wurde. Körnige Proben, die an der Kristalloberfläche geschmolzen und wieder gefroren waren, zeigten einen Strukturwechsel, der die Ionenfehlerdichte an der Oberfläche und die Leitfähigkeit der Probe erniedrigte.

Oberhalb $-25^{\circ} \mathrm{C}$ stimmte die Aktivierungsenergie für körnigen, eisartigen Schnee mit der für temperiertes Gletschereis und ein- und vielkristallines Laboreis überein, aber nicht mit der für Polarschnee oder Polareis. Unterhalb $-25^{\circ} \mathrm{C}$ stimmte die Aktivierungsenergie für körnigen Schnee mit der für temperiertes Gletschereis mit Verunreinigungen und der für Polarschnee und Polareis überein. Frische, trockene, temperierte Schneeproben zeigten niedrigere Aktivierungsenergien als Polarschnee in situ.

\section{INTRODUGtion}

Glen and Paren (1975) in their review on the electrical properties of snow and ice stated that the dielectric properties of snow from temperate regions have not usually been studied over a sufficiently wide temperature range to give good values of the activation energies for the conduction process. Without such data it is difficult to compare the electrical properties of temperate snow obtained under different conditions with those of either polar or temperate ice. 
We therefore have investigated the variation in conductivity and activation energy for a limited number of snow samples in the range of temperature from about $-10^{\circ} \mathrm{C}$ to $-80^{\circ} \mathrm{C}$. We measured the capacitance and the loss of a snow-filled capacitor using an a.c. bridge in the frequency range $0.5 \mathrm{kHz}$ to $40 \mathrm{kHz}$ and determined the real and imaginary parts $\epsilon_{\mathrm{r}}{ }^{\prime}$ and $\epsilon_{\mathrm{r}}{ }^{\prime \prime}$ of the complex permittivity of the snow sample. It was assumed that the dispersion satisfied the Debye relaxation equations. The conductivities at high frequency of the ice component $\sigma_{\mathrm{i}}$ ranged from about $\mathrm{IO}^{-4} \Omega^{-1} \mathrm{~m}^{-1}$ at temperatures near the melting point to about I0 $0^{-7} \Omega^{-1} \mathrm{~m}^{-1}$ at the lowest temperatures while the activation energy varied from about $0.6 \mathrm{eV}$ in the temperature range above $-25^{\circ} \mathrm{C}$ to about $0.2 \mathrm{eV}$ in the lower temperature range. It was found also that the conductivity $\sigma_{\mathrm{i}}$ depended on the snow structure and history, so that for example, dry powder snow showed a higher conductivity than wet snow, granular icy snow, or crushed laboratory ice crystals.

\section{Measurements}

Snow samples were collected locally between January and March 1977. The samples differed in their initial density on precipitation, texture, and grain size: they are listed in Table I. They were transferred to a capacitor that had been cooled below the melting point of ice and were packed at the densities of Table I. The wet snow samples 6 and 7 were precipitated at an air temperature close to $0^{\circ} \mathrm{C}$, the samples $\mathrm{I}, 2,3$, and 8 at $-5^{\circ} \mathrm{C}$, and the samples 4 and 5 at $-8^{\circ} \mathrm{C}$ : all samples, except 6 , were stored under refrigeration at $-5^{\circ} \mathrm{C}$. Laboratory snow (9) consisted of relatively large crystals of crushed ice from an ice machine.

TABle I. High Frequency CONDUCtivity of ICE

Sample
I
2
3
4
5
6
7
8
9

Snow description and age
New, dry, fine powder needles
Same type: compressed needles. I week
Same type and age as (2)
Powder, similar to ( 1$) .3$ weeks
Powder as (4). 9 weeks
Damp new snow. $2 \mathrm{~h}$
Same origin as $(6)$. Granular snow. $3 \mathrm{~d}$
Coarse granular icy firn. $4 \mathrm{~d}$
Laboratory crushed granular snow
s
ed snow ( $1-5)$
ples

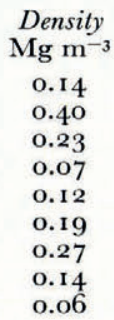

$E_{\mathrm{I}}$
$\mathrm{eV}$
$0.49 \pm 0.04$
$0.43 \pm 0.04$
$0.36 \pm 0.02$
$0.45 \pm 0.02$
$0.35 \pm 0.03$
$0.37 \pm 0.01$
$0.62 \pm 0.01$
$0.59 \pm 0.03$
$0.60 \pm 0.02$

$E_{2}$
$\mathrm{eV}$
$0.16 \pm 0.03$
$0.18 \pm 0.02$
$0.21 \pm 0.01$
$0.18 \pm 0.02$
$0.17 \pm 0.01$
$0.26 \pm 0.01$
$0.27 \pm 0.01$
$0.24 \pm 0.01$
$0.27 \pm 0.02$

$\begin{array}{cc}\sigma_{1}^{0} & \sigma_{2}{ }^{0} \\ \mathrm{M} \Omega^{-\mathrm{I}} \mathrm{m}^{-\mathrm{I}} & \mathrm{M}^{-1} \mathrm{~m}^{-\mathrm{I}} \\ 30 & 6 \\ \mathrm{I} 20 & 28 \\ \mathrm{I} 30 & 36 \\ 90 & 24 \\ 50 & 2 \mathrm{I} \\ 70 & 32 \\ 95 & 29 \\ 85 & 18 \\ 75 & 12\end{array}$

Mean values

Unmelted snow $(\mathbf{I}-5)$

Refrozen sn

$0.42 \pm 0.05$
$0.60 \pm 0.01$
$0.47 \pm 0.10$

$0.18 \pm 0.02$

$0.26 \pm 0.01$

$0.47 \pm 0.10 \quad 0.23 \pm 0.04$

$\begin{array}{ll}84 \pm 35 & 23 \pm 10 \\ 85 \pm 8 & 20 \pm 7 \\ 83 \pm 27 & 23 \pm 9\end{array}$

The capacitor consisted of four appropriately connected concentric hollow brass cylinders with an average separation of $0.05 \mathrm{~m}$ and had an air capacitance of $123 \pm 2 \mathrm{pF}$. The temperature was read to $\pm 2 \mathrm{deg}$ by a calibrated thermocouple inside the capacitor. The temperature of the snow-filled capacitor was varied by altering the rate at which the cold vapour from boiling liquid nitrogen passed round and through the capacitor. Measurements of capacitance and loss were taken with the capacitor both cooling and warming up, and were averaged to give values of $\epsilon_{\mathrm{r}}{ }^{\prime}$ with an error of $5 \%$, and $\epsilon_{\mathrm{r}}{ }^{\prime \prime}$ with an error which varied from $6 \%$ at high temperatures to $9 \%$ at low temperatures where the error in loss tangent was larger.

The Cole-Cole plots of $\epsilon_{\mathrm{r}}{ }^{\prime \prime}$ against $\epsilon_{\mathrm{r}}{ }^{\prime}$ for the laboratory snow and the dry and icy natural snow samples showed at all temperatures, but particularly at temperatures near the melting point, a marked deviation from the semicircular plot predicted for a single Debye dispersion process. This is illustrated in Figure I for some typical dispersion curves at a constant temperature of $-25^{\circ} \mathrm{C}$ for dry fine-grained snow (4) at a density of $0.18 \mathrm{Mg} \mathrm{m}^{-3}$, new damp snow (6) 
at a density of $0.27 \mathrm{Mg} \mathrm{m}^{-3}$, and laboratory snow (9) at a density of $0.06 \mathrm{Mg} \mathrm{m}^{-3}$. Ionic impurity effects are known to be responsible for this deviation at low frequencies. The impurity content of our samples was not determined, but it appeared to be higher than that of the snows studied by Kuroiwa (I962) and Keeler (I969). However our data approximated to a semicircle at higher frequencies so that the dominant Debye dispersion process with an appropriate activation energy was assumed to be operative in our samples.

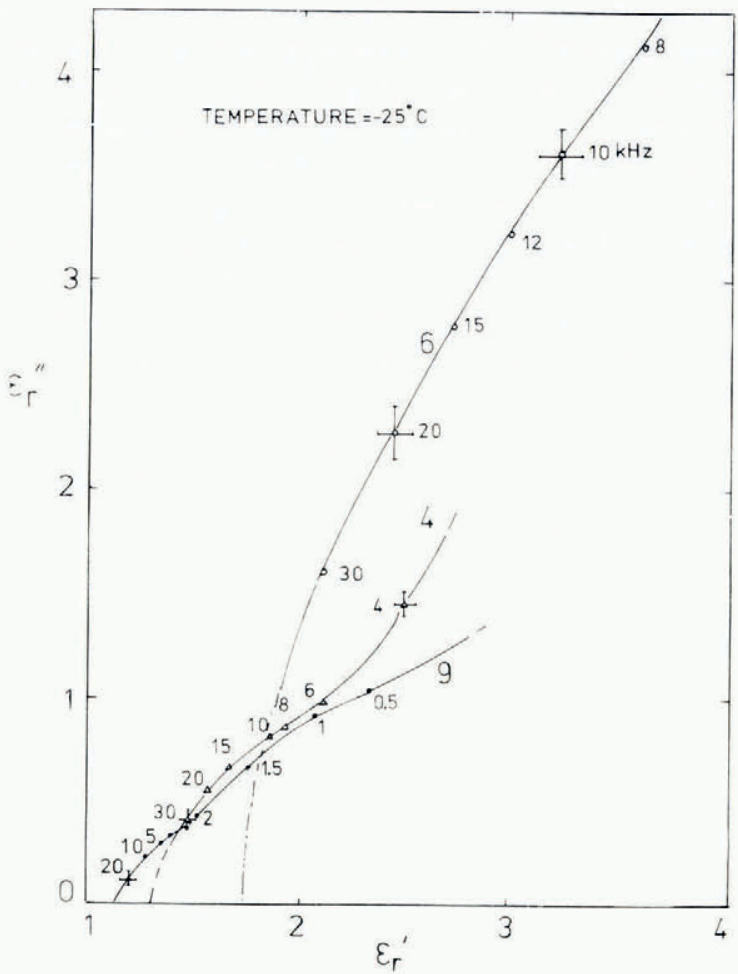

Fig. I. Complex plane permittivity plots for dry (4), wet (6), and laboratory (9) snows at constant temperature. Error bars are shown at selected points; frequencies are in $\mathrm{kHz}$.

We measured the conductivity in the high-frequency region. We checked that the conductivity of the laboratory snow at three constant temperatures, $-13^{\circ} \mathrm{C},-25^{\circ} \mathrm{C}$, and $-30^{\circ} \mathrm{C}$, was independent of frequency above about io $\mathrm{kHz}$ : our results therefore were assumed to be comparable with those of other workers (for example, see Glen and Paren's (1975) figure 2). The temperature dependence of conductivity also gave similarly shaped logarithmic plots for all frequencies beyond Io $\mathrm{kHz}$. However for some samples, such as (4) and (6) in Figure I, the conductivity was still frequency dependent up to the highest useable frequency of $30 \mathrm{kHz}$. All subsequent measurements were made at $20 \mathrm{kHz}$ in order to compare the conductivities at the same frequency. A comparison of the $\sigma_{20}$ values for the different snow samples also required that a suitable density correction be applied to bring their conductivities $\sigma_{20 \text { s }}$ to those of a corresponding solid ice conductivity $\sigma_{20 i} \cdot \sigma_{20 s}$ was determined from the measured $\epsilon_{\mathrm{r}}{ }^{\prime \prime}$ values, and $\sigma_{20 i}$ from a relationship (equation (Io), Glen and Paren, I975) based on a Looyenga model for a mixture of ice and air (Looyenga, 1965). This relationship has empirical applicability to snow with low loss at frequencies above the dominant ice relaxation spectrum; it also holds for d.c. conduction in snow (Bentley, 1977). Our approximation of using the measured 
$\epsilon_{\mathbf{r}}{ }^{\prime \prime}$ value in a simple equation rather than using the complex permittivity of snow in a more general equation can lead to a $\sigma_{20 \mathrm{i}}$ value smaller than it should theoretically be, but it gives a similar temperature dependence to the $\sigma_{20}$ value obtainable with the full equation. We checked the validity of the Looyenga (I 1965 ) equation $\epsilon^{\frac{1}{3}}-\mathbf{I}=v\left(\epsilon_{\mathbf{i}}^{\frac{1}{3}}-\mathbf{I}\right)$, where $v$ is the density ratio of snow to solid ice, and $\epsilon$ and $\epsilon_{\mathrm{i}}$ are the complex permittivities of snow and solid ice for similar fine grained samples $(\mathbf{I}, 2,3$, and 4$)$ at a fixed temperature. A plot of $\epsilon^{\frac{1}{3}}-\mathbf{I}$ against $v$ at $-57^{\circ} \mathrm{C}$ gave a straight line that cut the $v$ axis close to the origin at a density $0.010 \mathrm{Mg} \mathrm{m}^{-3}$, and gave a high frequency $\epsilon_{\mathrm{r}}{ }^{\prime}$ value at the density of ice in agreement with the accepted $\epsilon_{\infty}^{\prime}$ value for ice (Gough, 1972). The equation also held within the experimental error for a plot that used $\epsilon_{\mathrm{r}}^{\prime}$ instead of $\epsilon$, showing that the $\epsilon_{\mathrm{r}}{ }^{\prime \prime}$ contribution to $\epsilon^{\frac{1}{3}}$ was small. Our $\sigma_{20 \mathrm{i}}$ approximation appears to be reasonable, and we consider the use of the Looyenga density correction to be justifiable for a comparison of the $\sigma_{201}$ values for fine-grained snow. It was assumed to hold for granular snow, but this assumption, together with our approximation, should be remembered when considering the results of the next section.

It was not possible to obtain the static conductivity $\sigma_{0}$ from the a.c. measurements due to the high impurity content. We studied the d.c. conductivity for a limited number of samples in a separate experiment. The conductivity was derived from the maximum transient current

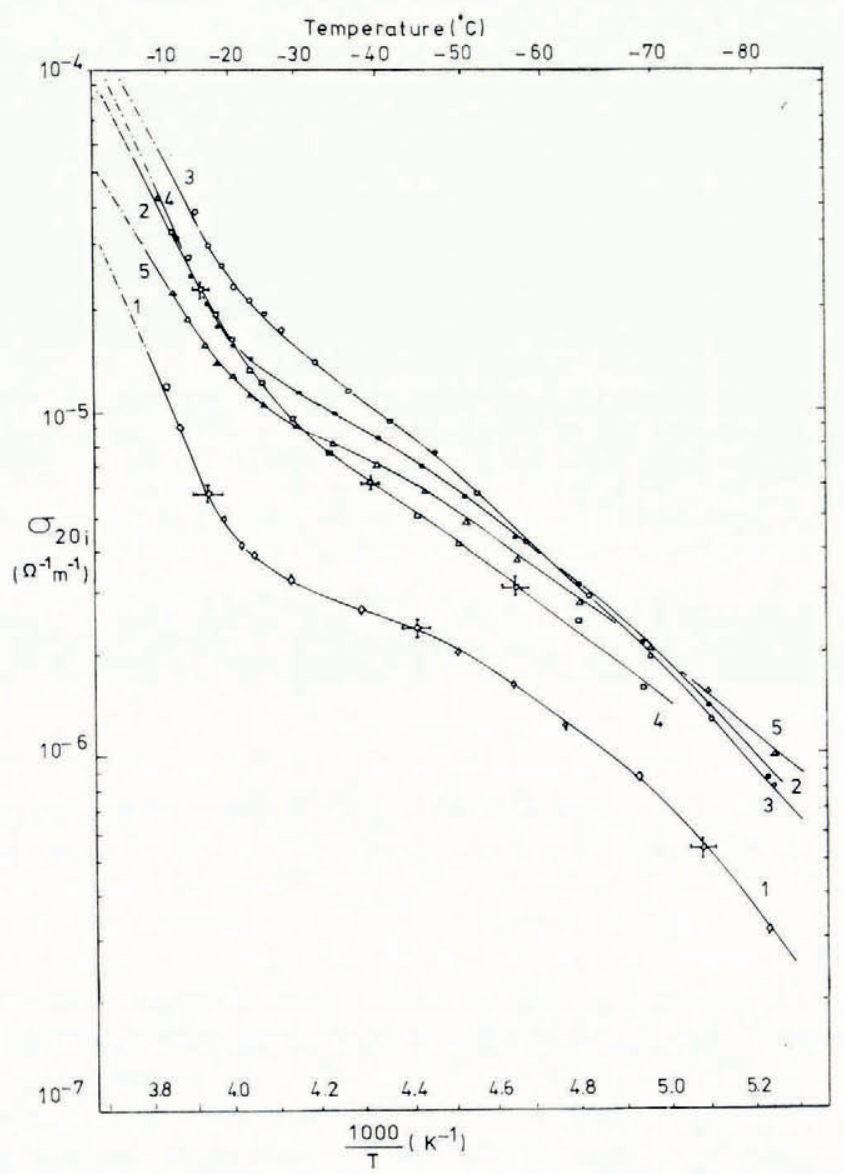

Fig. 2. The temperature dependence of the conductivity of ice deduced from data on fresh $(\mathrm{I})$ and aged (2-5) dry snow sample plotted logarithmically against reciprocal absolute temperature. Error bars are shown at selected temperatures. 
passing in about $0.5 \mathrm{~s}$ through a sample after a small d.c. voltage of the order of $\mathrm{I} .5 \mathrm{~V}$ had been applied to the snow-filled capacitor. The transient effect may have been associated with charge polarization effects within the sample. It was not related to the usual conduction processes. It was mainly of interest because the conductivity showed an unexpectedly marked and uniform temperature dependence.

\section{Results}

The conductivity $\sigma_{20}$ of each of the listed snow samples was determined over the temperature range $-\mathrm{Io}^{\circ} \mathrm{C}$ to $-80^{\circ} \mathrm{C}$. Limited measurements were made close to $o^{\circ} \mathrm{C}$ due to the possible existence of free liquid water between the grain boundaries. The variation of $\sigma_{20 i}$ with temperature is shown in the logarithmic plots of $\sigma_{20 \mathrm{i}}$ against the reciprocal absolute temperatures in Figures 2 and 3. The behaviour of fine-grained powder snow of different densities and ages is shown in Figure 2, and that of granular snow is shown in Figure 3.

Each snow sample showed certain general characteristics. There were two distinct temperature regions. The conductivity decreased rapidly down to a temperature between $-20^{\circ} \mathrm{C}$ and $-30^{\circ} \mathrm{C}$ and then showed a more gradual decrease down to the lowest temperatures. Each temperature region gave a different activation energy linked with a different

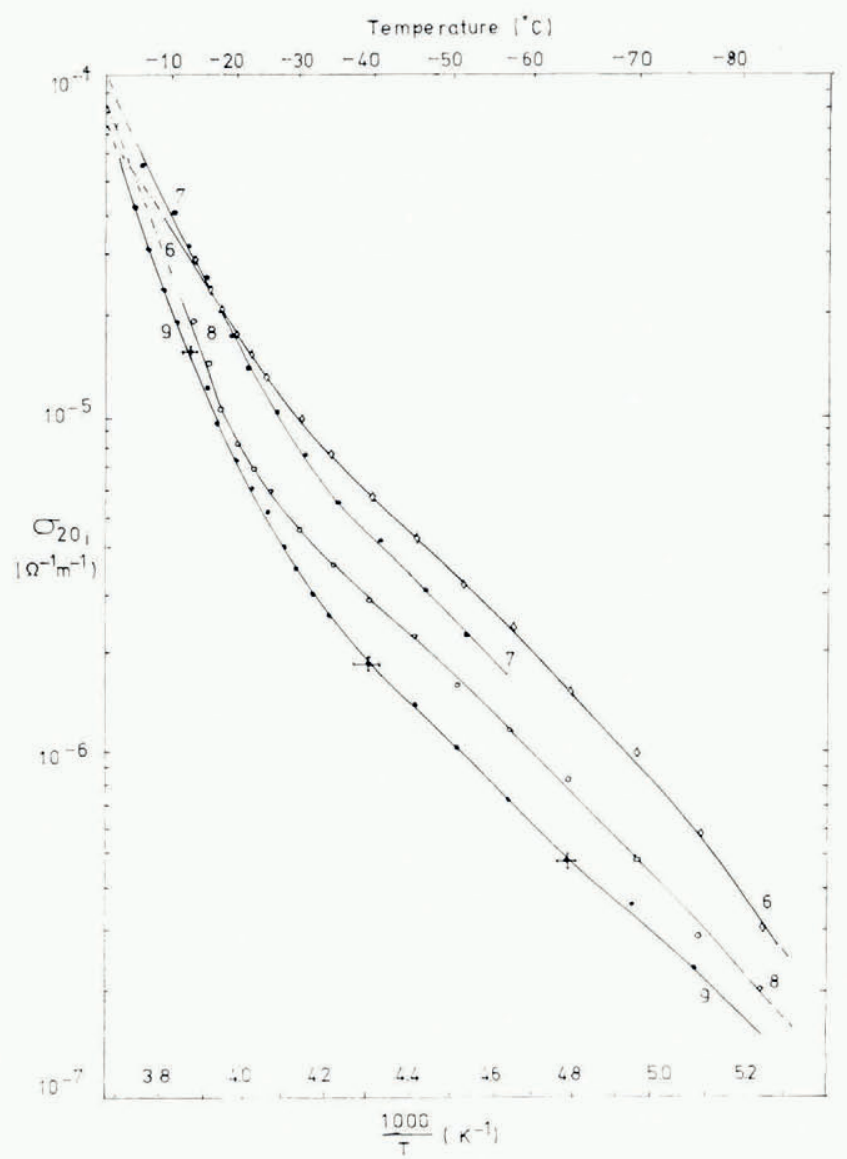

Fig. 3. The temperature dependence of the conductivity of ice deduced from data on moist (6), wet and refrozen $(7,8)$, and laboratory (9) snow samples plotted logarithmically against reciprocal temperature. Representative error bars are marked at certain points. 
physical process responsible for the conduction. The activation energies and their errors were evaluated by means of a least-squares computer programme which calculated the gradient and standard deviation of the experimental points over the two temperature ranges in the logarithmic plots of $\sigma_{20 \mathrm{i}}$ against the reciprocal temperature. The values are given in Table I.

Table I gives a brief description of the snow samples, the densities, the activation energies $E_{\mathrm{I}}$ and $E_{2}$ corresponding to temperatures above and below $-25^{\circ} \mathrm{C}$ respectively, and the $\sigma_{20 \mathrm{i}}$ conductivities, $\sigma_{1}{ }^{\circ}$ and $\sigma_{2}{ }^{\circ}$, obtained by an extrapolation to $0^{\circ} \mathrm{C}$ of the gradients of the two temperature regions of Figures 2 and 3 . The $\sigma_{20}$ values at $0^{\circ} \mathrm{C}$, and at $-20^{\circ} \mathrm{C}$ and $-50^{\circ} \mathrm{C}$ (not tabulated), enabled a comparison to be made of the conductivities of different snow types in the two temperature regions. The density values had an estimated $10 \%$ uncertainty due to inhomogeneous compression within the capacitor, while the extrapolated $\sigma_{1}{ }^{0}$ and $\sigma_{2}{ }^{0}$ values had average errors of $10 \%$ and $5 \%$ respectively. Table I also gives the mean values for both the activation energies and extrapolated $\sigma_{20 \mathrm{i}}$ values of the different snow types.

The variation of $\sigma_{20}$ with temperature for fine-grained snow samples is shown in Figure 2. These samples had been precipitated, collected, and then stored at a temperature below $\mathrm{o}^{\circ} \mathrm{C}$. They were free from any surface modifications caused by water, while any time-dependent intercrystalline metamorphism that leads to an ice network was modified during packing in the capacitor. The mean activation energies $E_{\mathrm{r}}$ and $E_{2}$ were $0.42 \pm 0.05 \mathrm{eV}$ and $0.18 \pm 0.02 \mathrm{eV}$. This value of $E_{2}$ assumes a constant gradient over the temperature range: this is not strictly correct, since the points fitted a best line which had an increasing curvature towards the lowest temperatures. This effect is most marked with new snow (I). Both $E_{1}$ and $E_{2}$ were independent of the sample age: they were lower than the activation energies derived from polar snow or firn. The extrapolated conductivities $\sigma_{1}{ }^{0}$ and $\sigma_{2}{ }^{0}$ were similar to those of other snows. Both the conductivities $\sigma_{20 s}$ and $\sigma_{20 \mathrm{i}}$ tended to increase with age. There were differences of $\sigma_{20 \mathrm{i}}$ between the sets $(1,2,3)$ and $(4,5)$ that had different origins. The older samples $(2,3)$ with the same origin and age but with differing densities, had higher $\sigma_{20 i}$ values than new snow (I) at all temperatures. They themselves had nearly identical $\sigma_{20 \mathrm{i}}$ values at low temperatures, but the lower-density snow (2) had a lower $\sigma_{20}$ value than (3) at temperatures above $-50^{\circ} \mathrm{C}$. However the situation was different with the set $(4,5)$, where the younger and less dense snow (4) now had a higher $\sigma_{20 \mathrm{i}}$ value at temperatures above $-30^{\circ} \mathrm{C}$, and changed to having the lower, rather than an identical, $\sigma_{20 \mathrm{i}}$ value to $(5)$ at lower temperatures. Definite conclusions are uncertain with these limited sample numbers. The differences between the samples were partly due to the way the Looyenga equation was applied, but as will be noted later it also seems important to consider the role of absorbed and adsorbed impurities on the snow crystals in the conduction processes.

The variation of $\sigma_{20 \mathrm{i}}$ with temperature for coarser-grained snows is shown in Figure 3 . The structure and texture of the natural snow samples had been superficially modified by the formation and subsequent freezing of water on and between the crystals: (6) was fresh damp snow, (7) older coarser grained wet refrozen and stored snow, and (8) larger grains of icy firn that had thawed and refrozen before collection. The activation energies $E_{\mathrm{I}}$ and $E_{2}$ of the slightly modified damp snow (6) were similar to those of unmelted samples $(\mathrm{I}-5)$. The activation energies $E_{\mathrm{I}} \approx 0.6 \mathrm{eV}$ and $E_{2} \approx 0.25 \mathrm{eV}$ of the modified natural snow samples $(7,8)$ were the same as those for laboratory snow (9). At temperatures above $-25^{\circ} \mathrm{C}$ the mean value $E_{\mathrm{I}}=0.60 \pm 0.05 \mathrm{eV}$ for samples 7,8 , and 9 was similar to that for temperate glacier ice and laboratory single crystals. At temperatures below $-25^{\circ} \mathrm{C}$ the mean activation energy $E_{2}=0.26 \pm 0.0 \mathrm{I} \mathrm{V}$ was similar to that obtainable from temperate glacier ice containing impurities (Glen and Paren, 1975, fig. 3) and of laboratory finely-ground ice aged in air (Paren and Glen, I978). It may be noted that both polar snow and ice have similar activation energies $E_{2} \approx 0.24 \mathrm{eV}$ (Glen and Paren, I975, table I and figs 9 and 10 ; Fitzgerald and Paren, 1975). It was found that conductivity $\sigma_{201}$ of laboratory snow (9) was lower than 
that of natural snow $(6,7$, and 8$)$. For all samples $(6-9) \sigma_{201}$ increased with increasing density and with decreasing grain size. The greater the volume proportion of ice in the snow and the greater the surface area of the ice grains, the greater was the conductivity. The modified icy samples $\left(7,8\right.$ and 9) showed the same $\sigma_{20 \mathrm{i}}$ trends, while the behaviour of damp snow (6) had also some similarities to that of dry snows $(I-5)$.

A comparison of the conductivities of unmelted samples $(\mathrm{I}-5)$ and of melted and refrozen samples (6-9) showed some marked differences. Fresh damp snow (6) had higher conductivities $\sigma_{20 \mathrm{~s}}$ and $\sigma_{20 \mathrm{i}}$ than new fine-grained dry snow (I) at all temperatures. This was in agreement with d.c. conductivity measurements on alpine snow and névé (Kopp, I962). Although the moist snow crystals were assumed to have a smaller total surface area than dry snow, the main effect of surface modification associated with a water film formed temporarily on the crystals was to increase $\sigma_{20 \mathrm{i}}$. Any decrease in surface area of damp snow was more than balanced by an increase in the surface impurity content and hence in $\sigma_{20 i}$. On the other hand the ageing of the samples had little effect in the higher temperature region, but it increased $\sigma_{20 \mathrm{i}}$ for unmelted samples $(2-5)$ and decreased $\sigma_{20 \mathrm{i}}$ for modified samples $(7-9)$ in the lower temperature region. This was consistent with the adsorption of impurities such as $\mathrm{CO}_{2}$ on the surface, in which for unmelted snows the total surface area remained approximately constant but was greater than that of the modified snows.

The d.c. measurements of the temperature dependence of the conductivity gave some anomalously higher "activation energies" in the range $-4{ }^{\circ} \mathrm{C}$ to $-20^{\circ} \mathrm{C}$. The values measured to $\pm 0.05 \mathrm{eV}$ were $\mathrm{I} .33 \mathrm{eV}$ for compressed dry snow (2), $1.25 \mathrm{eV}$ for moist snow (6), and $2.06 \mathrm{eV}$ for laboratory snow (9). These large "activation energies" were higher than those of the order of $0.8 \mathrm{eV}$ found by Kopp (1962) for d.c. surface conduction in a quasi-fluid film on the grains in alpine snows and névé. They were associated with values of $\sigma_{\mathrm{s}}{ }^{0} \approx$ ro $\mathrm{M} \Omega^{-1} \mathrm{~m}^{-1}$ and with Looyenga density-corrected $\sigma_{\mathrm{i}}$ values that were greater than those measured by Kopp or listed in Table I. The uncorrected conductivity $\sigma_{\mathrm{S}}$ of dry snow (2) was higher than that of either damp snow (6) or laboratory snow (9) at all temperatures. These effects were related to transient space-charge currents in the samples.

\section{Discussion}

We discuss our results qualitatively in terms of the main conduction processes that occur in the ice crystals.

It is considered that the variation of the dielectric permittivity of an ice crystal with frequency in the higher audio-frequency range is governed primarily by a simple Debye-type dispersion. The dispersion parameters are determined by the conductivities that result from the combined movement of the $\mathrm{D}$ and the $\mathrm{L}$ Bjerrum defects and the ionic $\mathrm{H}_{3} \mathrm{O}^{+}$and $\mathrm{OH}^{-}$ defects through the ice lattice. The permittivity is associated with the rotation of molecules caused by the migration of Bjerrum defects between adjacent bonds in the crystal. The conductivity is related to the movement of protons that cause the ionic defects to migrate along the linking bonds in the ice structure. The presence of dissolved ionic impurities in the lattice changes both the number of these ionic defects and their activation energy. They can also change the relative numbers of Bjerrum and the ionic defects so that their respective roles can be reversed in the conduction process. If this happens the ionic defects then become the majority carriers and are responsible for the permittivity while the Bjerrum defects become the minority carriers in the conduction process. It is assumed that the conduction in both ice and snow is associated with these processes, although this is complicated in snow by the surface conduction outside and between the individual snow grains. The surface conduction must operate in parallel with the volume conduction process within the crystal itself.

We apply these ideas of our results. We conclude that the temperature dependence of the conductivity showed that the importance of Bjerrum-defect conduction at temperatures below 
the melting point decreased towards the lower temperatures, while at the same time the importance of the ionic-defect conduction increased so that it dominated conduction at the lowest temperatures. This change in the relative importance of the conduction mechanisms took place at a temperature close to that associated with the change in the activation energy. These changes have been seen previously in certain laboratory ice experiments (Camp and others, 1969) and with polar ice samples (Paren, r 973).

Our results in the low-temperature region showed that a crucial factor in the conduction of a snow sample was the grain size and hence the number of separate crystals per unit volume. While it was not possible to know whether these changes in grain size altered the number density of the defects or the mobilities of the Bjerrum and ionic defects, or wert due to the migration of some other non-equilibrium defects such as dislocations, it may be explained qualitatively by considering the role of the surface of the crystals in the various sam les. Dry fine-grained crystalline snow samples had a larger surface area than the wet modified snow samples. The surface area was reduced by the melting of the surface of the samples and the freezing of the superficial water in snow. It is suggested that the adsorption of impurities from the atmosphere and their diffusion into the crystal increased the impurity concentration, and the resultant increase in the ionic defect concentration contributed to the increase in the conductivity. The existence of a surface itself may also contribute to the generation of the higher-mobility Bjerrum L defects and so lead to the higher conductivity of the sample, although the role of both types of Bjerrum defects will have decreased at the temperatures where the surface effects had become more noticeable.

The effect of temperature on the number of ionic defects was to decrease their concentration at low temperatures. This showed up as a tendency for the activation energy to increase at the lowest temperatures. Such effects have been observed in pure ice by Camp and others (1969), who observed that the d.c. conductivity was independent of temperature down to about $-50^{\circ} \mathrm{C}$ and then fell sharply at lower temperatures. The increase in the conductivity with the age of a snow sample suggested that the concentration of ionic defects or impurities or both increased with time.

The importance of surface impurities should be considered also in the d.c. measurements. They indicated that if the current depended on the impurities then the impurity content of dry unmodified snow was higher than that of wet modified or laboratory snow. Similar effects have been observed in natural snow (Kopp, I962), and by Camp and others (1969) in laboratory experiments on thin ice rods with deliberate surface contamination. Camp and others suggested that the simultaneous occurrence of their high conductivities and high activation energies might be due to a disordered region close to the surface with a high conductivity and a temperature-dependent thickness. If such a process had contributed to our transient measurements, the changing geometry of such a surface region might have altered the conductivity by ionic defects and hence accounted for the anomalously high activation energy. The role of surface impurities needs to be investigated in further transient-current experiments.

Our a.c. and d.c. measurements indicated that the properties of the crystal and grain surfaces and the role of impurities were important in the mechanism of conduction in snow. A comparison of temperate and polar snows showed that they have similar ionic-defect conduction properties at low temperatures. The main difference between the equilibrium properties of temperate and polar snow appeared to be the presence of a Bjerrum defect conduction process with a higher activation energy at temperatures close to the melting point in temperate snow and the absence of this process in polar snow.

\section{REFERENCES}

Bentley, C. R. 1977. Electrical resistivity measurements on the Ross Ice Shelf. Fournal of Glaciology, Vol. 18, No. 78 , p. ${ }^{1} 5^{-35}$. 
Camp, P. R., and others. 1969. Electrical conduction in ice, [by] P. R. Camp, W. Kiszenick, D. Arnold. (In Riehl, N., and others, ed. Physics of ice: proceedings of the international symposium on physics of ice, Munich, Germany, September 9-14, 1963. Edited by N. Riehl, B. Bullemer, H. Engelhardt. New York, Plenum Press, p. 450-70.)

Fitzgerald, W. J., and Paren, J. G. 1975. The dielectric properties of Antarctic ice. Fournal of Glaciology, Vol. 15 , No. 73 , p. $39^{-4} 4^{8}$.

Glen, J. W., and Paren, J. G. 1975. The electrical properties of snow and ice. Journal of Glaciology, Vol. 15, No. 73 , p. $15-38$.

Gough, S. R. 1972. A low temperature dielectric cell and the permittivity of hexagonal ice to 2 K. Canadian fournal of Chemistry, Vol. 50, No. 18 , p. 3046-51.

Keeler, C. M. 1969. Some physical properties of alpine snow. U.S. Cold Regions Research and Engineering Laboratory. Research Report $27 \mathrm{I}$.

Kopp, M. 1962. Conductivité électrique de la neige, au courant continu. Zeitschrift für angewandte Mathematik und Physik, Vol. 13, Fasc. 5, p. 431-41.

Kuroiwa, D. 1962. Electrical properties of snow. (In Bader, H., and Kuroiwa, D. The physics and mechanics of snow as a material. U.S. Cold Regions Research and Engineering Laboratory. Cold regions science and engineering. Hanover, N.H., Pt. II, Sect. B, p. $63^{-79 .)}$

Looyenga, H. I965. Dielectric constants of heterogeneous mixtures. Physica, Deel 31, No. 3, p. $401-06$.

Paren, J. G. 1973. The electrical behavior of polar glaciers. (In Whalley, E., and others, ed. Physics and chemistry of ice: papers presented at the Symposium on the Physics and Chemistry of Ice, held in Ottawa, Canada, I4-I8 August 1972. Edited by E. Whalley, S. 7. Jones, L. W. Gold. Ottawa, Royal Society of Canada, p. 262-67.)

Paren, J. G., and Glen, J. W. 1978. Electrical behaviour of finely divided ice. Journal of Glaciology, Vol. 21 , No. 85, p. $173-91$. 